\title{
Analysis of the parameters of the fire modeled in a road tunnel
}

\author{
Omar LANCHAVA ${ }^{1,2}$, Nicolae ILIAS ${ }^{3}$, Sorin Mihai RADU ${ }^{3}$, Leon MAKHARADZE ${ }^{1,2}$, \\ Teimuraz KUNCHULIA ${ }^{2}$, Nino ARUDASHVILI ${ }^{2}$, Zaza KHOKERASHVILI ${ }^{2}$ \\ ${ }^{1}$ G. Tsulukidze Mining Institute, 7, Mindeli Street, Tbilisi, Georgia \\ ${ }^{2}$ Georgian Technical University, 77i, Kostava Street, Tbilisi, Georgia \\ ${ }^{2}$ University of Petrşani, 20, Universităţii Street, Petroşani, Romania
}

\begin{abstract}
The essence of the problem lies in the experimental study of the laws governing the changes in the aerodynamics of air flow and the most important ventilation parameters, taking into account the effect of fire. During the experiments, the aerodynamics of the tunnel is complicated by the presence of additional resistance, and the variables will be: the slope of the tunnel, the heat release rate, the cross section of the tunnel, the ratio of the width of the tunnel to the height, the fill factor of the tunnel by transport. The solution to the problem is an improved ventilation technology in case of fires to save lives. The aim of the research is to study the critical velocity, the backlayering length and the gradient-factor using numerical and physical models, as well as mathematical analysis for the downward movement of fresh air, when the fresh air inlet is above the fire level. The scale of the physical models is 1:40 and 1:60. Numerical models are full scale using of modern engineering technique Pyrosim and Fluent. The generalization of the results is carried out using piece-wise constant functions. The obtained results are also be compared with similar results known from scientific literature.
\end{abstract}

Key words: road tunnel model, critical velocity, backlayering length, Froude number, transformable element

\section{Introduction}

The parameters of modeled and real fires in the tunnels, such as critical velocity, backlayering length and gradient-factor, are possible to study by means of numerical and physical models and mathematical analysis. In case of a descending movement of fresh air, an opposite movement of smoke and other combustion products - the reflux - is particularly evident. Critical velocity and length of reflux are important technological parameters of ventilation, which determine the methods of evacuation and types of firefighting measures. 
Critical velocity is determined as a minimum speed of longitudinal ventilation, which excludes the formation of a smoke back flux. The length of reflux is the distance of propagation of smoke and toxic combustion products in the descending fresh air current. A gradient-factor is determined as the coefficient showing the rate of increase of critical velocity and length of reflux depending on the tunnel gradient. A ventilation system collapse is a state of a ventilation system when the direction and intensity of the air movement in the tunnel is determined by the traction formed as a result of fire in terms of decreased mechanical ventilation traction, following the condition of their algebraic summation.

Over 50 road tunnels must be built in Georgia in the nearest 3-5 years and as their design solutions suggest, the only risk-factor of an expected threat is fire. This problem is recognized internationally as well. By considering the strong fires in the tunnels of the world, the European Union paid particular attention to the Trans-European Network (TEN) recognizing the safety of the existing and planned tunnels as a priority.

For the TEN tunnels with their length exceeding $500 \mathrm{~m}$, the European Parliament and the European Council issued Directive EC2004/54 regarding the minimum level of safety. The length of such tunnels in the EU countries is more than $1000 \mathrm{~km}$. The EU countries were strongly recommended to apply the Directive requirements to the tunnels beyond TEN. In fact, the minimum safety level is given as organizational and technical requirements to the tunnels for fire safety.

Under Directive EC2004/54, fire safety expenses for road tunnels in the EU countries vary between $€ 2.6-6.3$ billion. $€ 2.6$ billion is needed for the ventilation systems and their improvement technology associated with fewer expenses under the Directive [1-4].

As already mentioned, the essence of the problem is to determine the important technological parameters of regularities of variation of air current aerodynamics and ventilation in a tunnel under the impact of fire for different tunnel gradients, heat emissions, tunnel cross sections, tunnel width and height ratios and tunnel traffic filling ratios and in terms of complicated tunnel aerodynamics due to extra barriers in the tunnel as transformable elements to prolong the evacuation time. By solving the problem, the tunnel ventilation technology to save lives in case of fire will be improved. Consequently, the given study results are of a social nature and serve the purpose of improved safety. 


\section{Models and methods of analysis}

\subsection{Description of physical modeling by using the Froude criterion}

Modeling by using the Froude criterion is widely used in the experiments with fires. A particular feature of this method is that the Froude number characterizing the forces of inertia and gravity, will be given in the experiments as it is. In case of modeling by using the Froude number, the temperature field is the same and the scale of heat emission, depending to the geometrical scale of the model and the nature, is expressed as follows

$$
\begin{aligned}
& \frac{Q_{m}}{Q_{n}}=\left(\frac{\ell_{m}}{\ell_{n}}\right)^{\frac{5}{2}}, \\
& \frac{u_{m}}{u_{n}}=\left(\frac{\ell_{m}}{\ell_{n}}\right)^{\frac{1}{2}},
\end{aligned}
$$

Where $Q_{m}, Q_{n}$ are the convectional heat emissions for model and natural conditions, respectively, $\mathrm{kW} ; \ell_{m}, \ell_{n}$ are the lengths of the tunnel for model and nature, respectively, $\mathrm{m} ; u_{n}, u_{m}$ are air velocities for model and natural conditions, respectively, $\mathrm{m} / \mathrm{s}$.

The series of experiments were done for the physical model of tunnels with three different cross sections (See Fig. 1). The impact of fire on critical velocity, backlayering length and ventilation collapse probability for longitudinal ventilation with the engagement of transformable elements in the model was studied. The tunnel coverage ratio with the transformable element was 0$100 \%$.

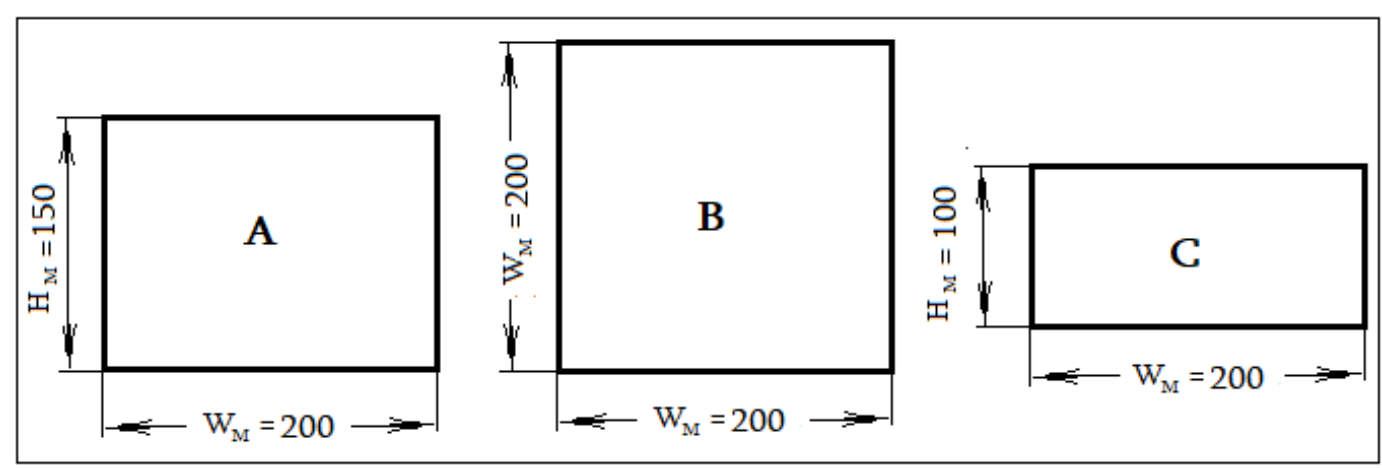

Fig. 1. Cross sections of tunnels of A, B and C types, linear scale: 1:40; areas of cross sections of the model: $0.03 ; 0.04$ and $0.02 \mathrm{~m}^{2}$ respectively, corresponding to the areas of cross sections in natural conditions: $48 ; 64$ and $32 \mathrm{~m}^{2}$ 
The plans given in Fig. 2-9 are common for all of them. It is easy to see that the area of the tunnel cross section varies for different options. In case of a physical model, the tunnel length is 12 m (480 m naturally), which is supplied with air by means of an isolated inventory air duct (See Fig. 7 and 8).

A rectangular cross section of models of types $\mathrm{A}, \mathrm{B}$ and $\mathrm{C}$ was taken to determine the tunnel coverage ratio by a transformable element relatively accurately. Consequently, the study of the impact of the shape of a tunnel on such sought quantities as critical velocity and backlayering length, is not considered by the physical experiments. Rather, this will be done by numerical modeling.

We separate the convenience of using the Froud number for modeling and the inadmissibility to use a permanent value of the Froud number for all strengths of fires [5]. In this connection, reference [6] too notes that the use of critical Froude number $F r=4.5$ is not justified to calculate the critical velocity or backlayering length to control smoke for all capacity of fires. The same opinion is partially implied in works [7-13].

We choose only linear scale $M_{l}=l_{m} / l_{n}=W_{M} / W_{N}=H_{M} / H_{N}=0.025$ for physical modeling.

Other scales of modeling are calculated by the given formulae:

Scale of heat emission, as calculated with formula (1), is $M_{Q}=0.0000988$;

Scale of ventilation rate, as calculated with formula (2), is $M_{u}=0.158$.

The given scales will be maintained for all three types of a model.

The tunnel model was made with 1 mm-thick stainless-steel sheets. Two types of vehicles: Nissan Patrol 2014, with natural sizes 5160X1995X1938 $\mathrm{mm}$ and Euro truck sized $13600 \times 2450 \times 2450 \mathrm{~mm}$ positioned in the central part, are common for all models.

By considering the linear modeling scale, the sizes of model vehicles will be: 130X50X50 mm (Nissan Patrol 2014) and 340X60X60 mm (Euro truck). The vehicle will be positioned in the tunnel symmetrically. The distance between the bed of the vehicles and the tunnel floor will be 0.02 $\mathrm{m}(20 \mathrm{~mm})$ on the model corresponding to $0.8 \mathrm{~m}(800 \mathrm{~mm})$ natural size. Transformable elements will be placed $3.25 \mathrm{~m}$ on the both sides from the seat of fire corresponding to $300 \mathrm{~m}$ natural distance. 


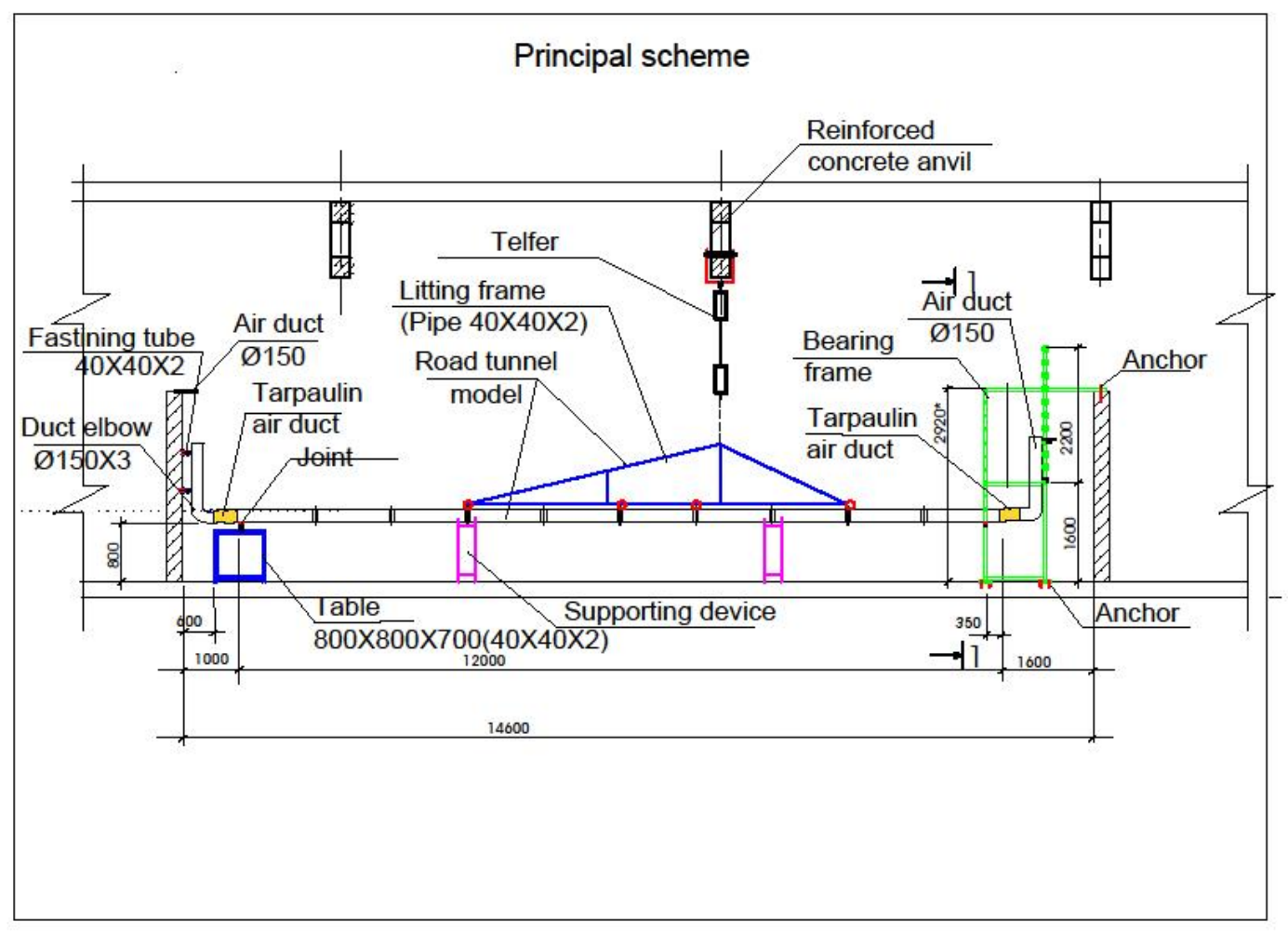

Fig. 2. General view of the tunnel model, hoisting machine and location of accessories

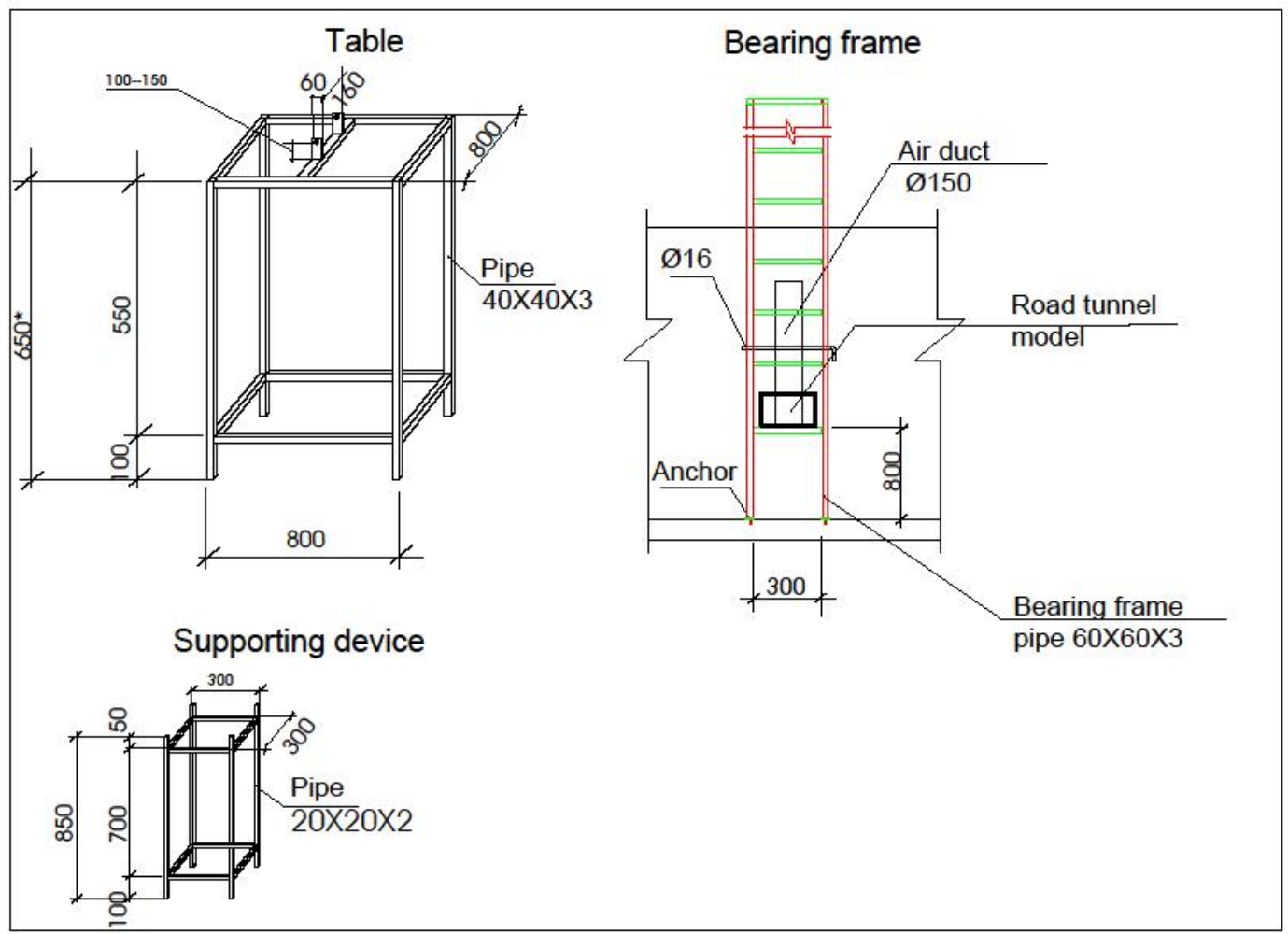

Fig. 3. Tunnel model accessories 


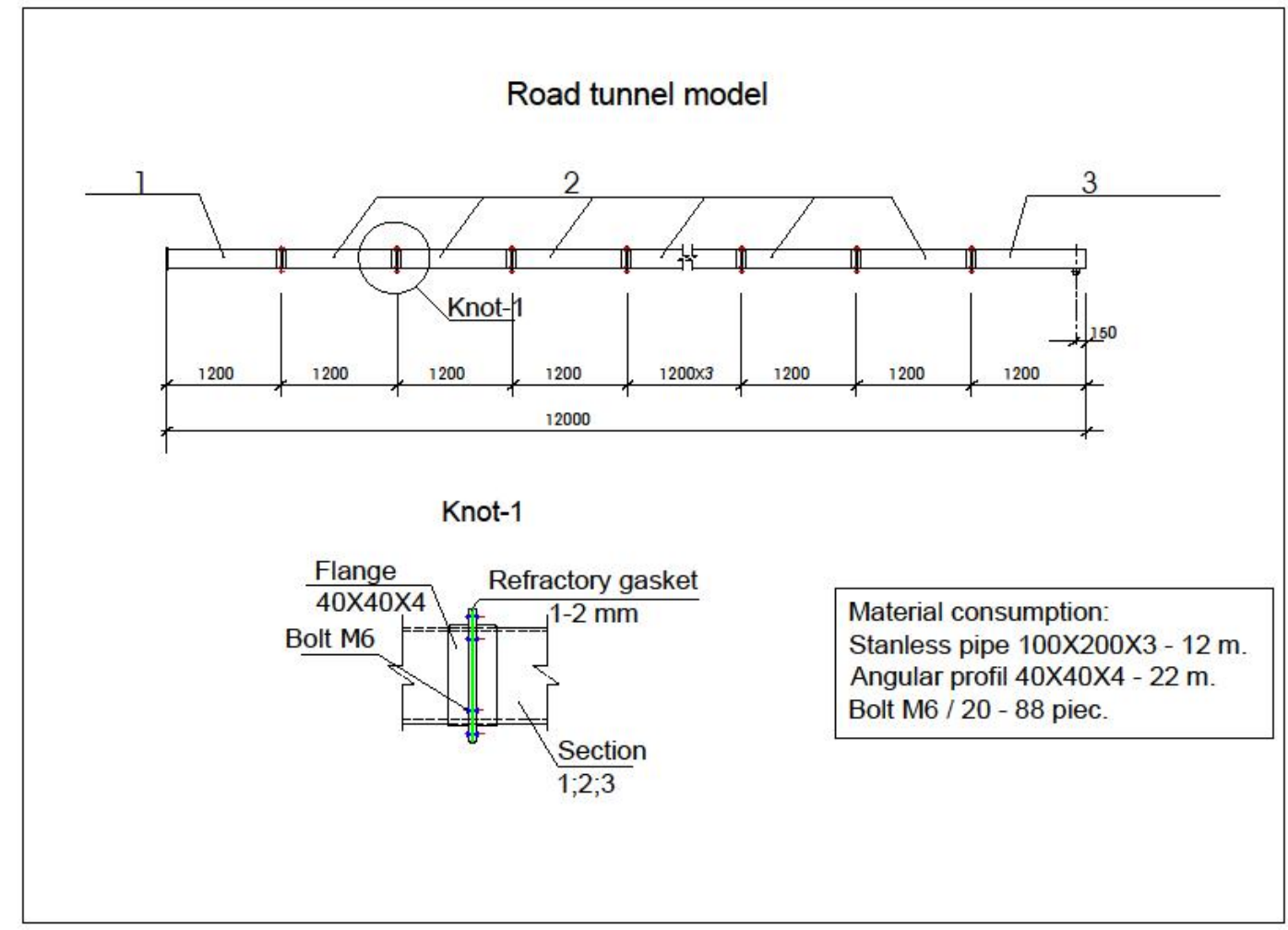

Fig. 4. Connection plan of individual blocks of a road tunnel

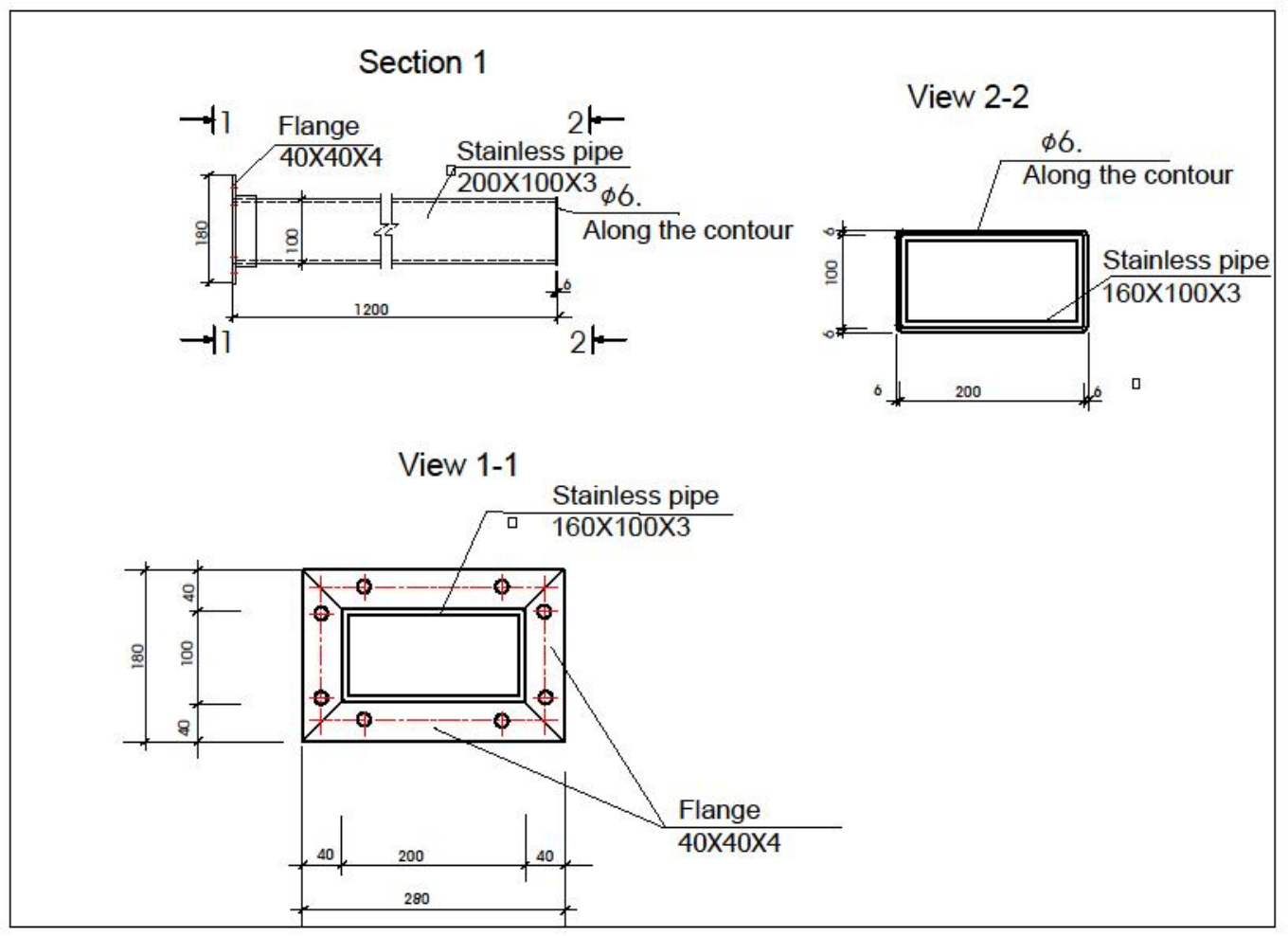

Fig. 5. Section 1 of the tunnel model 
Section 2

View 1-1

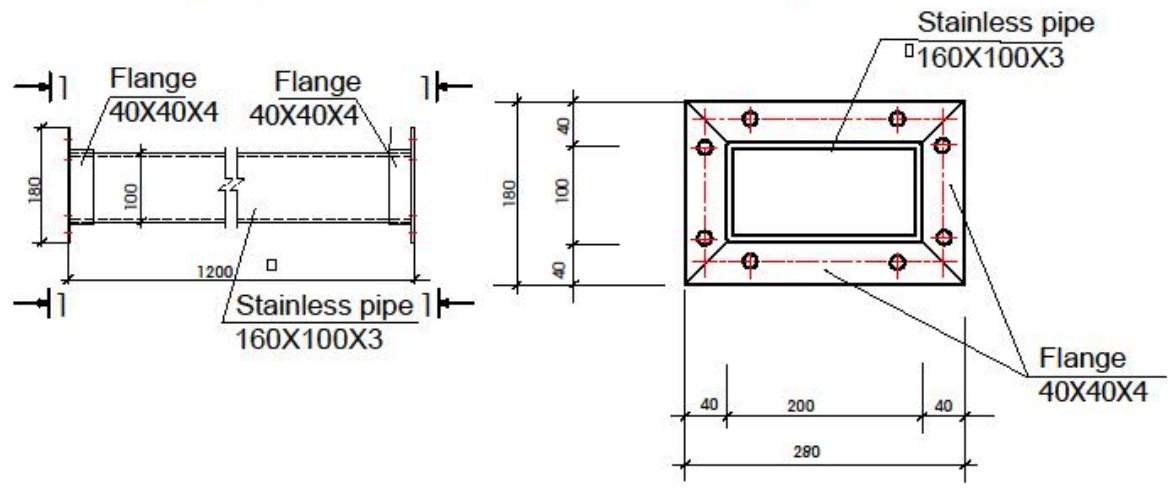

Fig. 6. Section 2 of the tunnel model

Section 3

View 1-1

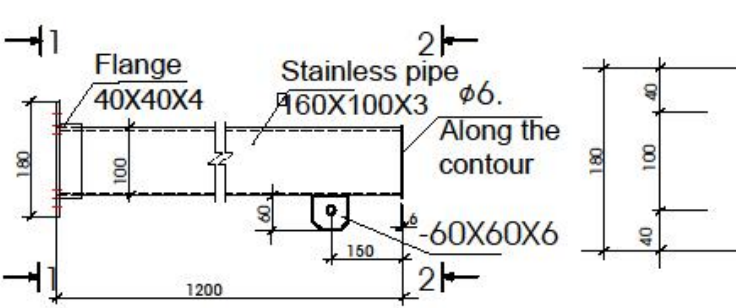

View 2-2

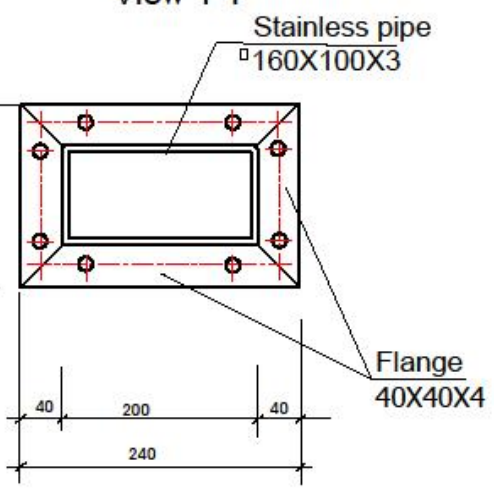

$\phi 6$

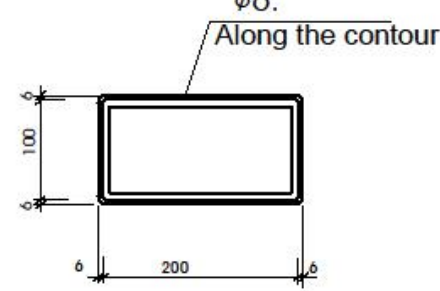

Fig. 7. Section 3 of the tunnel model 


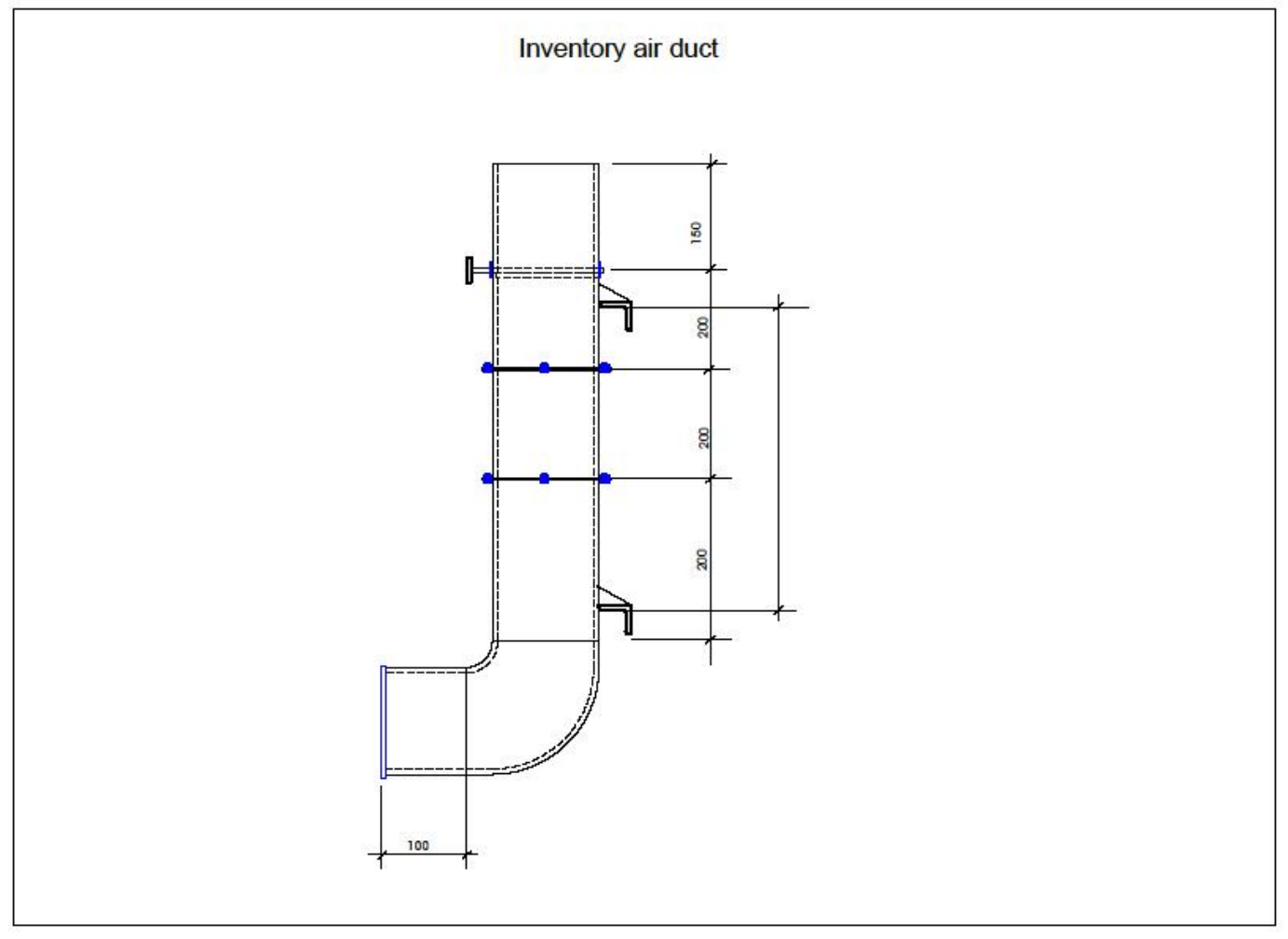

Fig. 8. Inventory air duct

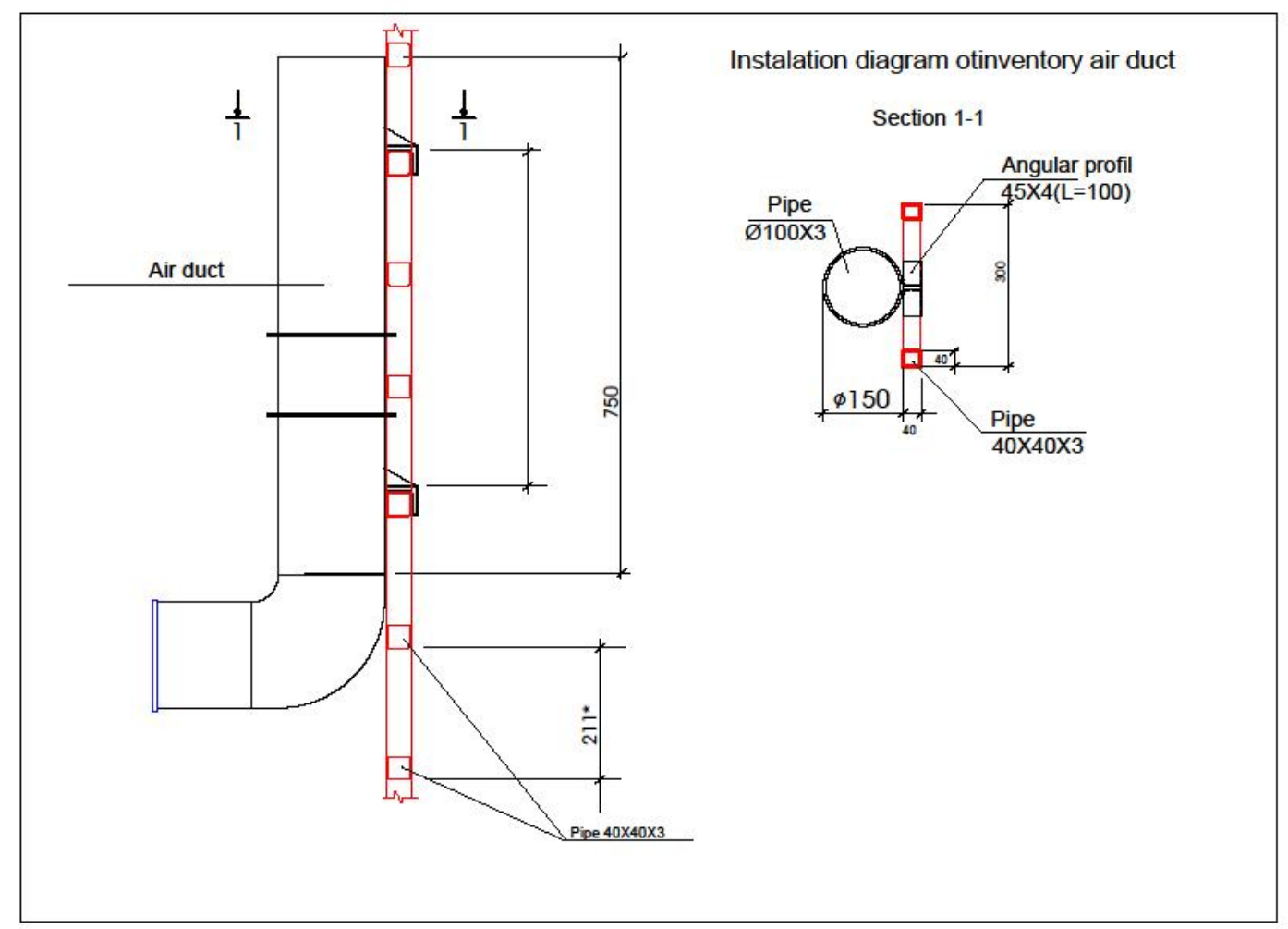

Fig. 9. Plan of installation of the inventory air duct 
Stable turbulence in the tunnel will be provided by using a static pressure chamber with the length of $1 \mathrm{~m}$, with the width of $0.5 \mathrm{~m}$ and with the height of $0.5 \mathrm{~m}$, supplied with air from the duct fan with $20-150 \mathrm{~m}^{3} / \mathrm{h}$ consumption and up to $150 \mathrm{~Pa}$ maximum static pressure for model A. Porous burners with $130 \times 50 \mathrm{~mm}$ and $340 \times 60 \mathrm{~mm}$ surface area will serve as a source of fire. The surface of the fire source will be at the tunnel floor level. Natural gas will be used as fuel with its consumption measured to $1 \%$ accuracy. There will be single- or double-porous burners located in the tunnel section. Heat emission on the model is calculated by considering the air consumption. The air consumption in the tunnel will be calculated with a flow meter with $1 \%$ accuracy. The air consumption rate varies within the limits of $20-150 \mathrm{~m}^{3} / \mathrm{h}$. Air velocity is not measured, but is calculated by considering the air consumption and tunnel cross section.

\subsection{Model tunnel indices in nature}

The indices of the tunnel of type A shown in Drawing 1 will be as follows naturally: cross section $S_{N}=48 \mathrm{~m}^{2}$; tunnel width: $W_{N}=8 \mathrm{~m}$; tunnel height: $H_{N}=6 \mathrm{~m}$; the sizes of the same indices of a model are as follows: $S_{M}=0.03 \mathrm{~m}^{2}$; width: $W_{M}=0.20 \mathrm{~m}$, and height: $H_{M}=0.15 \mathrm{~m}$.

Linear measures of the model and the natural object for tunnels of type A, together with the areas of cross sections are shown in Table 1. We do not give similar tables for other types of tunnels.

Table 1

Linear measures of the model $(\mathrm{M})$ and the natural object $(\mathrm{N})$

\begin{tabular}{|c|c|c|c|c|c|}
\hline Name & $\begin{array}{l}\text { Length, } \mathrm{m} \\
(\mathrm{mm})\end{array}$ & $\begin{array}{l}\text { Width, } \mathrm{m} \\
(\mathrm{mm})\end{array}$ & $\begin{array}{l}\text { Height, } \mathrm{m} \\
(\mathrm{mm})\end{array}$ & $\begin{array}{l}\text { Cross } \\
\text { section, } \mathrm{m}^{2}\end{array}$ & Note \\
\hline Tunnel (N) & $\begin{array}{c}480 \\
(480,000)\end{array}$ & $8.0(8,000)$ & $6.0(6,000)$ & 48.0 & - \\
\hline Tunnel (M) & $12(12,000)$ & $0.20(200)$ & $0.15(150)$ & 0.03 & - \\
\hline Vehicle (N) & $\begin{array}{c}13.6 \\
(13,600)\end{array}$ & $2.45(2,450)$ & $2.45(2,450)$ & 6.0 & Euro truck \\
\hline Vehicle (M) & $0.34(340)$ & $\begin{array}{c}0.0613 \\
(613)\end{array}$ & $0.0613(613)$ & 0.00375 & Euro truck \\
\hline Vehicle (N) & $5.16(5,160)$ & $\begin{array}{c}1.995 \\
(1,955)\end{array}$ & $\begin{array}{c}1.938 \\
(1,938)\end{array}$ & 3.87 & $\begin{array}{c}\text { Nissan } \\
\text { Patrol 2014 }\end{array}$ \\
\hline Vehicle (M) & $0.13(130)$ & $0.05(50)$ & $0.05(50)$ & 0.0025 & Nissan-P2014 \\
\hline
\end{tabular}

The ratio of the tunnel width to the tunnel height for different models varies between 1,0 and 2.0. In particular, for type A tunnel, $A R=W_{M} / H_{M}=1.33$; for type $B$ tunnel: $A R=1.0$ and for type $C$ tunnel: $A R=2.0$. 


\subsection{Tunnel traffic filling ratio}

Tunnel traffic filling ratio $\alpha$ for different models is calculated as follows

$$
\alpha=\frac{F}{f},
$$

Where, is the cross section of a vehicle, $\mathrm{m}^{2} ; f$ - is the tunnel cross section, $\mathrm{m}^{2}$.

The limits of variation of the tunnel traffic filling ratio according to the experiments are given in Table 2.

Table 2

Numerical values of tunnel traffic filling ratio $\alpha$

\begin{tabular}{|c|c|c|c|}
\hline $\begin{array}{c}\text { Type of a } \\
\text { tunnel model }\end{array}$ & \multicolumn{3}{|c|}{$\begin{array}{c}\text { Numerical values of } \alpha \text { depending on the number of vehicles in the section of } \\
\text { the tunnel model, \% }\end{array}$} \\
\cline { 2 - 4 } & 1 Nissan Patrol 2014 & 1 Euro truck & 2 Euro trucks \\
\hline$A$ & 8.3 & 12.5 & 25.0 \\
\hline$B$ & 6.3 & 9.4 & 18.8 \\
\hline$C$ & 12.50 & 18.75 & 37.50 \\
\hline
\end{tabular}

For tunnel of type $A$, filling ratio $\alpha=12.5-25.0 \%$; for tunnel of type $B: \alpha=9.0-18.0 \%$ and for tunnel of type $C: \alpha=18.75-37.50 \%$.

Thus, the limits of variation of the tunnel traffic filling ratio are $6.3-37.50 \%$ in the planned experiments.

\subsection{Air velocities for the model and naturally}

Air consumption for tunnels of types A and B will be $20-150 \mathrm{~m}^{3} / \mathrm{h}$ and $20-100 \mathrm{~m}^{3} / \mathrm{h}$ for the tunnel of type $\mathrm{C}$.

The summary data for all three types of tunnels are given in Table 3.

Table 3

Variation limits of air speed numerical values for the model and in nature

\begin{tabular}{|c|c|c|c|}
\hline Tunnel model type & $\begin{array}{c}\text { Air consumption, } \\
\mathrm{m}^{3} / \mathrm{hr}\end{array}$ & $\begin{array}{c}\text { Air velocity of the } \\
\text { model, } \mathrm{m} / \mathrm{sec}\end{array}$ & $\begin{array}{c}\text { Air velocity in natural } \\
\text { terms, } \mathrm{m} / \mathrm{sec}\end{array}$ \\
\hline$A$ & $20-150$ & $0.185-1.389$ & $1.2-8.8$ \\
\hline$B$ & $20-150$ & $0.139-1.041$ & $0.9-6.6$ \\
\hline$C$ & $20-100$ & $0.278-1.389$ & $1.8-8.8$ \\
\hline
\end{tabular}

For a type-A tunnel, in terms of air consumption of $20 \mathrm{~m}^{3} / \mathrm{h}$, the speed for the model will be $u_{m}=0.185 \mathrm{~m} / \mathrm{s}$, what, as formula (2) suggests, implies natural speed $u_{n}=1.2 \mathrm{~m} / \mathrm{s}$. In terms of air 
consumption of $150 \mathrm{~m}^{3} / \mathrm{h}$, the speed for the model will be $u_{m}=1.389 \mathrm{~m} / \mathrm{s}$, what, as formula (2) suggests, implies natural speed $u_{n}=8.8 \mathrm{~m} / \mathrm{s}$.

The low speeds of a model are translated into higher natural speeds by means of the Froude number, which greatly differs from the Reynolds number in this respect.

\subsection{Heat emission of the model and in nature}

The convenience of modeling by using the Froude number is particularly clear when comparing the model and natural values of heat emission. In particular, as PIARC recommends, road tunnel ventilation systems must be designed to neutralize the products of $30 \mathrm{MW}$ or stronger fires [2, 3]. Modeling of a $30000 \mathrm{MW}$ fire by using the Froud number needs only $2.964 \mathrm{~kW}$ strength by considering the above-indicated scale $M_{Q}=0.0000988$.

Following the above-mentioned, the possibility of simple and swift modeling of higher speed and stronger fire for the given tunnel model is evident. In particular, by using the Froude criterion, it is possible to do a fire experiment in safer conditions of less temperature.

\subsection{Positive and negative directions of ventilation}

As the depression caused by fire and the fan's depression sum up algebraically, an issue to select the positive and negative directions of the ventilation current movement in the inclined tunnels may be presented in regular terms.

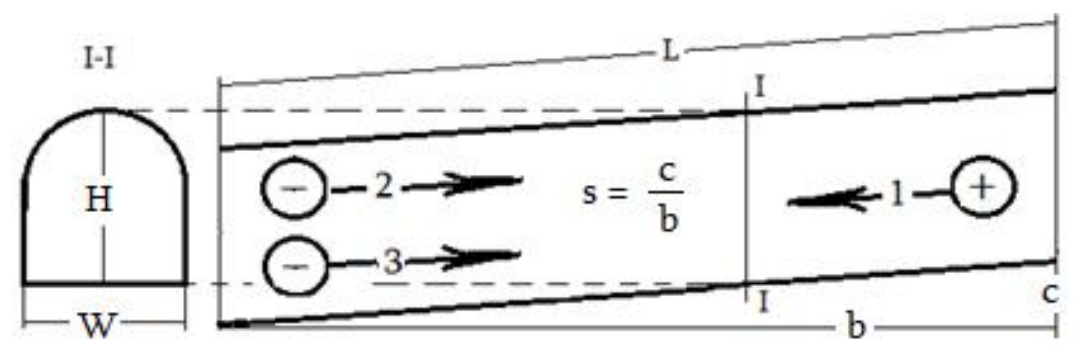

Fig. 10. Directions of fresh air movement and combustion products depending on the tunnel gradient: 1 - Positive (descending) direction of fresh air movement, 2 - Negative (ascending) direction of fresh air movement, 3 - Natural (negative and ascending) direction of combustion products movement, $\mathrm{L}$ - tunnel length, $\mathrm{m} ; \mathrm{W}$ - tunnel width, $\mathrm{m} ; \mathrm{H}$ - tunnel height, $\mathrm{m} ; \mathrm{b}$ - horizontal projection of the tunnel length, $\mathrm{m} ; \mathrm{c}$ - vertical height of gradient, $\mathrm{m} ; \mathrm{s}$ - tunnel gradient, \%.

As fire is a negative event in general, the traction caused by fire must be considered negative as well. Consequently, a positive ventilation direction will be opposite, i.e. when the fresh air inlet is 
located hypsometrically higher than the seat of fire. So, the positive direction of fresh air movement is descending and its negative movement is ascending. The natural direction of the combustion products movement is always ascending and negative (See Fig. 10).

As different scientific literature gives it, conditionally, both, the ascending and the descending currents are taken as positive and negative directions of the ventilation current sometimes causing inconvenience from the point of view of unambiguity.

\subsection{Ensuring tunnel gradient}

The limits of a tunnel gradient are: $-10^{0}<\mathrm{s}<10^{\circ}$. Each degree gives $1.75 \%$ gradient. Gradient will be ensured with a special telpher and model-retaining equipment (See Drawings 2 and $3)$.

The free end of the model has a lug, which will be placed and fixed in a proper pocket. The deviation of the model from the horizontal plane in degrees is given in Table 4 .

Table 4

Vertical deviation of the model from the horizontal plane to provide $-10^{0}<\mathrm{s}<10^{0}$ gradient

\begin{tabular}{|c|c|c|c|c|c|c|c|}
\hline $\begin{array}{c}\text { Angle of } \\
\text { inclination, } \\
0\end{array}$ & $\begin{array}{c}\text { Vertical } \\
\text { distance, } \\
\mathrm{m}\end{array}$ & $\begin{array}{c}\text { Angle of } \\
\text { inclination, } \\
0\end{array}$ & $\begin{array}{c}\text { Vertical } \\
\text { distance, } \\
\mathrm{m}\end{array}$ & $\begin{array}{c}\text { Angle of } \\
\text { inclination, } \\
0\end{array}$ & $\begin{array}{c}\text { Vertical } \\
\text { distance, } \\
\mathrm{m}\end{array}$ & $\begin{array}{c}\text { Angle of } \\
\text { inclination, } \\
0\end{array}$ & $\begin{array}{c}\text { Vertical } \\
\text { distance, } \\
\mathrm{m}\end{array}$ \\
\hline-1 & -0.21 & -6 & -1.25 & 1 & 0.21 & 6 & 1.25 \\
\hline-2 & -0.42 & -7 & -1.46 & 2 & 0.42 & 7 & 1.46 \\
\hline-3 & -0.63 & -8 & -1.67 & 3 & 0.63 & 8 & 1.67 \\
\hline-4 & -0.84 & -9 & -1.88 & 4 & 0.84 & 9 & 1.88 \\
\hline-5 & -1.05 & -10 & -2.08 & 5 & 1.05 & 10 & 2.08 \\
\hline
\end{tabular}

Thus, the amplitude of movement in a vertical plane is $2.08 \mathrm{~m}$, and the sweep is $4.16 \mathrm{~m}$.

\subsection{Backlayering determination}

Backlayering is determined depending on temperature, by means of stainless-steel thermocouples of type $\mathrm{k}$. The location plan of thermocouples is given in Fig. 11. Critical velocity is determined by analyzing the length of reflux, with extrapolation of the relevant curve. The thermocouples in all model tunnels will be installed $20 \mathrm{~mm}$ below the ceiling, all along the ascending and descending currents. 40 thermocouples will be installed on both sides of the tunnel center, along 2-meter-long sections (making total $4 \mathrm{~m}$ ) so that the distance between their axes is 0.1 
$\mathrm{m}$. The thermocouples with $0.2 \mathrm{~m}$ intervals will also be installed along the remained length of the model tunnel. The total number of thermocouples for any model is 80 .

The readings of thermocouples will be taken by means of online surveillance system.

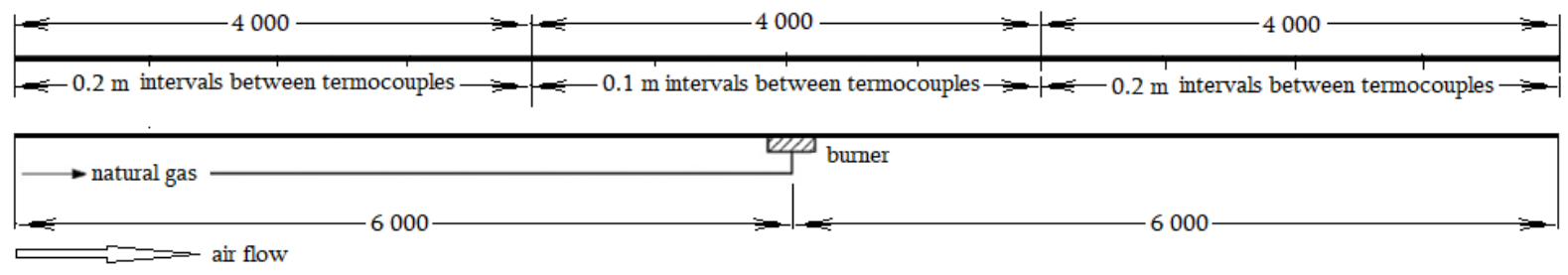

Fig. 11. Location of thermocouples according to the length of the experimental equipment

The goal of the experiment is to study the impact of transformable systems on the variation of the numerical values of critical velocity and backlayering length and to develop relevant correlations by considering the jamming of the tunnel with vehicles. The fire will be modeled not within the vehicle model, but outside it, below the model, and the flame will surround all the perimeter of the vehicle model or a part of it according to the planned tasks.

The critical velocity in an inclined tunnel will be studied by means of the above-described natural and numerical experiments (computer modeling). This will be done to validate the natural and numerical experiments and to draw relevant conclusions. The gradient of the experimental tunnel will be up to 10 degrees. As far as we know, there is a tunnel with an 8-degree gradient in Norway, while the maximum gradient of the tunnels in China is 7 degrees [14].

We can only note in advance that depending on the length of a tunnel and following a tunnel gradient, the combustion products propagate asymmetrically and such asymmetry is more in highly inclined tunnels. Consequently, the given experiments must demonstrate the reality of traffic tunnels.

At this point, we deliberately choose not to consider mining tunnels with higher gradients, if not talking about vertical shafts.

\subsection{Experimental determination of gradient-factors}

The gradient-factors are experimentally determined by means of the following formula

$$
K_{g}=\frac{u_{c, \theta}}{u_{c, 0}}
$$


Where, $u_{c, 0}$ is the critical velocity at zero gradient, $\mathrm{m} / \mathrm{sec} ; u_{c, \theta}-$ is the critical velocity in case of gradient angle $\theta$. We will note that using formula (4) is posisble both, for analyzing and correlating the results of physical modeling.

\subsection{Experimental check of the expected collapse of the ventilation system}

In case of strong fire, the impact of fans operation on the ventilation flow is diminished after some time notwithstanding the direction of impact of high temperature - be that increased dynamic pressure or reduced air density caused by fire or both. So, a collapse is a process of dominant dynamic pressure occurrence and propagation comparable with the tunnel ventilation system depression caused by strong and violently progressing fire. It should be noted that the dynamic pressure developed by fire algebraically sums up with fan pressure.

The scientific literary sources give various evaluations of the impact of fire intensity on ventilation. The results given in paper [15] are relatively close to the idea of the present article.

This issue is planned to clarify by varying tunnel gradient and fire emission indicator. The Clapeyron ideal-gas law will serve as a theoretical base.

\section{Results and validation of models}

Simultaneously with the physical experiments, the numerical modeling of the same problems will be provided and the sizes of model cells will be determined by comparing the gained results. A full-scale numerical modeling will be possible to provide more thoroughly in respect of specifying the model cells.

The results of the planned study, transformable systems and regularities of a critical velocity, backlayering length and gradient-factor variation will be applicable in safe operation of the motor tunnels of Georgia. As for the development and sustainability of the country economy, it much depends on a trouble-free operation of the transport network. A tunnel is a key element of a transport network, as it is the means to overcome the most difficult sections on the road. Therefore, the planned studies must be unilaterally important for Georgia and the given scale does not diminish the significance of the expected outcomes. However, we consider that the problem is much more important and the gained results must be applicable in other similar cases. 
As it is known, due to complexity, the critical velocity and backlayering length in inclined tunnels are less studied and their values are calculated by using the available results of horizontal tunnels [19].

The formula to calculate the critical velocity $u_{C}$ in inclined tunnels uses the numerical value of critical velocity $u_{c, 0}$ of horizontal tunnels as per the following equation [14]

$$
u_{c, \theta}=K_{g} u_{c, o}
$$

Where $K_{g}$ is a gradient-factor used for inclined tunnels in case of fire.

NFPA 502 offers an equation of a gradient-factor for inclined tunnels [20]

$$
K_{g}=1+0.0374 s^{0.8},
$$

Where $s$ is the tunnel gradient (\%) determined by the ratio of the height of elevation to the horizontal length (See Drawing 2). In other words, if angle is $\theta$, the tunnel gradient is $\operatorname{tg} \theta$. Value $s$ in formula (6) is a gradient given in percentage, i.e. $s=100 \operatorname{tg} \theta$.

Critical velocity may be calculated by formula

$$
u_{\mathrm{c}}=\mathrm{k}\left(\frac{\mathrm{g} \dot{\mathrm{Q}}_{\mathrm{c}} \mathrm{H}}{\rho_{0} \mathrm{c}_{\mathrm{p}} \mathrm{TA}}\right)^{1 / 3},
$$

Where $\mathrm{k}$ is the proportionality constant; $g$ is the gravitatinal acceleration, $\mathrm{m} / \mathrm{s}^{2} ; \dot{\mathrm{Q}}_{\mathrm{c}}$ is the convenctional heat emited as a result of fire, $\mathrm{kW} ; \mathrm{H}$ is the tunnel height, $\mathrm{m} ; \rho_{0}$ is the density of outer air, $\mathrm{kg} / \mathrm{m}^{3} ; \mathrm{c}_{\mathrm{p}}$ is the air specific heat, $\mathrm{kJ} /(\mathrm{kg} . \mathrm{K}) ; \mathrm{T}$ is the mean smoke temperature, $\mathrm{K}$; $\mathrm{A}$ is the area of the tunnel cross section, $\mathrm{m}^{2}$.

The proportionality constant is calculated by formula

$$
\mathrm{k}=\operatorname{Fr}_{C}^{-\frac{1}{3}}
$$

Where $\mathrm{Fr}_{C}$ is critical Froude number calculated by formula

$$
F r_{C}=\frac{\Delta \rho g H}{\rho_{0} u_{C}^{2}}
$$

Where in addition to the expaliend values, $\Delta \rho$ is the density difference between the outer air and the smoke, $\mathrm{kg} / \mathrm{m}^{3}$.

Mean smoke temperature is calculated by formula 


$$
\mathrm{T}=\mathrm{T}_{0}+\frac{\dot{\mathrm{Q}}_{\mathrm{c}}}{\rho_{0} \mathrm{c}_{\mathrm{p}} \mathrm{Au}}
$$

Where in addition to the expaliend values, $\mathrm{T}_{0}$ is the external air tempeature, $\mathrm{K}$.

It should be noted that in order to determine the critical velocity with formula (7), the values of mean temperature and proportionality constant are needed. Formulae (8)-(10) to calculate them contain sought value $u_{C}$. To solve this issue, the critical Froude number equaling 4.5 was introduced what simplifies the calculation. As we will see below, this is not a real solution to the problem.

Thomas was the first to link the critical velocity of reflux to the Froude criterion [21] by noting that the nature of flow of the combustion products and air mixture depends on the ratio between the smoke gravity and the inertial forces of the ventilation flow expressed by the Froude criterion, and introduced $\mathrm{Fr}_{c}=1$ as a numerical value of the criterion received by low alcohol flame.

Lee et al. [22] studied the fire in the aerodynamic pipe caused by $0,3 \times 0,3 \times 10 \mathrm{~m}$ firewood obstruction and noted that the aerodynamic resistance on the seat of fire increased 6-fold for a ventilation current and approximately by 1,5 times on both sides, beyond the fire. Reflux occurred when the speed of a throttled ventilation current on the seat of fire was $0,6 \mathrm{~m} / \mathrm{sec}$ what corresponded to the numerical value of the Froude criterion of $F r_{c} \approx 7$.

Danziger and Kennedy [23], without studying the processes incompletely, expecting that like the Reynolds number, the Froude number would have a critical numerical value, introduced 4.5 as a critical numerical value as if after the paper by Lee et al., which for years was a subject of discussion of many authors regarding the critical velocity and distance of reflux. Report by Kennedy "Critical velocity: Past, present and future" presented in London in 1996 at seminar "Smoke and Critical Velocity in Tunnels" is a similar work [24].

The given admission simplifies the question, as in this case, under formula (7), coefficient $\mathrm{k}$ $=0.606$, but it is not right.

Figure 12 shows that the numerical value of the critical number varies within $2.5-3.2 \mathrm{~m} / \mathrm{s}$ provided $\mathrm{Fr}_{c}=4.5$. Thus, the maximum value of critical velocity is $3.2 \mathrm{~m} / \mathrm{s}$ and there is no problem, but indeed, the range of variation of critical speed is much greater (See Fig. 13) and consequently, the Froude critical number has not a constant value. 


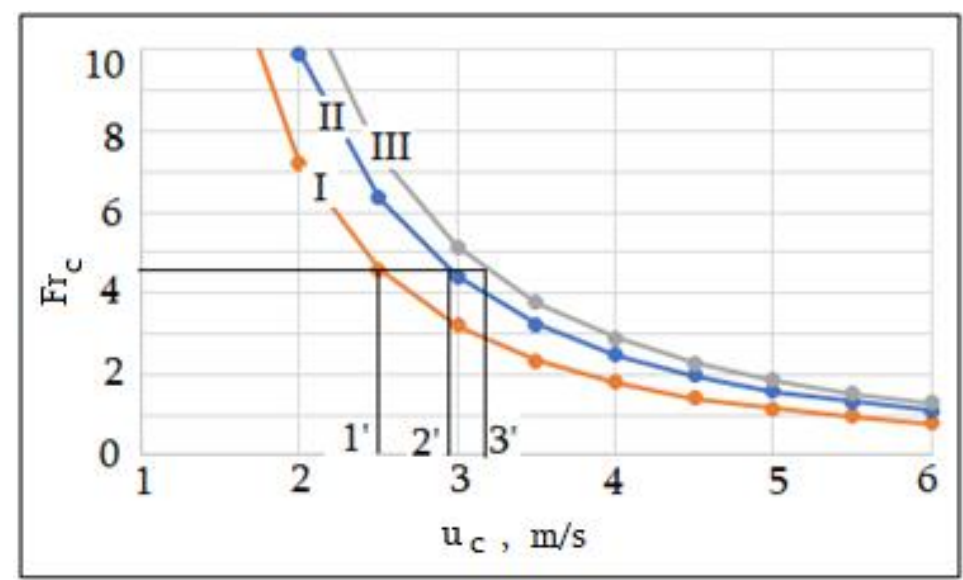

Fig. 12. Variation of the critical Froude number depending on critical velocity when tunnel height is $6 \mathrm{~m}$; tunnel cross section is $50 \mathrm{~m}^{2}$; outer air temperature is $293 \mathrm{~K}$ and I - 573; II - 903; III - $1373 \mathrm{~K}$ in line with mean smoke temperatures, respectively

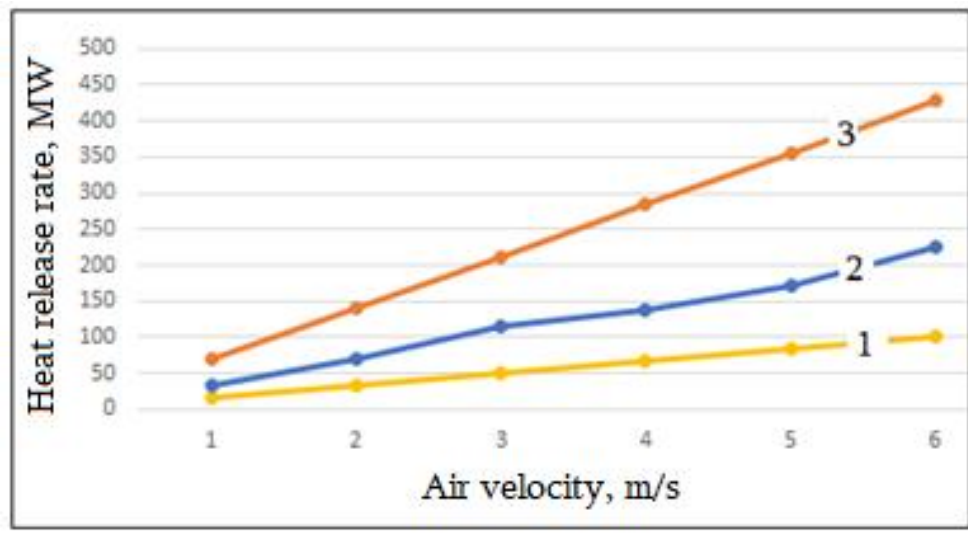

Fig. 13. Variation of fire intensity controlled by ventilation depending on air velocity when tunnel height is $6 \mathrm{~m}$; tunnel cross section is $50 \mathrm{~m}^{2}$; outer air temperature is $293 \mathrm{~K}$ and I - 573; II - 903; III $-1373 \mathrm{~K}$ in line with mean smoke temperatures, respectively

Following the above-mentioned, it is clear that despite a number of advantages of using the Froude number for physical modeling of fires, the opportunity to use it for the purposes of generalization or correlation of the results must be evaluated negatively because of reduced accuracy even in case of applying piecewise constant functions. In addition, it should be noted that even in the case of strong fires, non-observance of the constancy of the numerical value of the Froude criterion shown in Fig. 12 and 13 are the case, while in case of small fires the use of the Froude criterion for correlation purpose must be excluded because of poor accuracy. 


\section{Conclusions}

- Based on the presented results, we can assume that the physical model of the tunnel is convenient to do the experiments, as the use of Froude criterion allows studying the scenarios of strong fires on the example of small fires what makes experiments cheaper without diminishing the safety.

- The important technological properties, such as determination of the air current critical velocity and backlayering length, correlating their values to tunnel gradient, tunnel vehicular filling ratio, strength of fires and other important typical parameters what also allows validating numerical objectives can be determined by means of physical modeling.

\section{Acknowledgements}

This work was supported by Shota Rustaveli National Science Foundation (SRNSF) [Grant number AR-19-1936, Project title "Development and testing of transformable system to save life in road tunnel in case of fire"].

\section{References}

[1] A. Beard, R. Carvel (2012) Handbook of Tunnel Fire Safety, Second edition, Thomas Telford Limited, p. 678.

[2] D. Theologitis (2005) Euro transport, \# 3. pp. 16 - 22.

[3] UN, Economic and Social Council, Economic Commission for Europe (2001) Report TRANS/AC.7/9. p. 59.

[4] UN, Economic and Social Council, Economic Commission for Europe (2002) Report TRANS/AC.7/11. p. 6.

[5] O. Lanchava (2019) ANALYSIS OF CRITICAL AIR VELOCITY FOR TUNNEL FIRES CONTROLED BY VENTILATION. Mining Journal N1 (42), pp. 126-132, Tbilisi (in Georgian).

[6] Y.Z Li., H. Ingason (2018) Discussions on critical velocity and critical Froude number for smoke control in tunnels with longitudinal ventilation. Fire Safety Journal, Vol. 99, pp. 22-26.

[7] O. Lanchava, E. Medzmariashvili, N. Ilias, G. Khitalishvili, Z. Lebanidze (2009) Prospects of usage of transformable systems for extinguishing fire in tunnels. International Scientific Conference "Advanced Lightweight Structures and Reflector Antennas”, Tbilisi, pp. 301-308.

[8] O. Lanchava, G. Nozadze, N. Bochorishvili, Z. Lebanidze, N. Arudashvili, M. Jangidze, K. Tsikarishvili (2014) Criteria for evaluation of emergency firefighting in transport tunnels. "Transport Bridge Europe-Asia", Materials of International Conference, Tbilisi, pp. 29-35.

[9] O. Lanchava, G. Nozadze, N. Arudashvili (2015) ANALIZE OF FATAL FIRES IN TRANSPORT TUNNELS AND MEASURES OF ITS PREVENTING. Mining Journal N2 (35), pp. 85-89, Tbilisi (in Georgian).

[10] O. Lanchava, G. Nozadze, N. Arudashvili (2016) THE NATURAL AERODYNAMIC OBSERVATION RESULTS OF THE CHAKVI-MAKHINJAURI ROAD TUNNELS. Mining Journal N1 (36), pp. 61-63, Tbilisi (in Georgian).

[11] O. Lanchava, N. Ilias, G. Nozadze (Jan 2017) Some problems for assessment of fire in road tunnels. Quality Access to Success, Vol. 18, S1, pp. 69-72. 
[12] N. Ilias, O. Lanchava, G. Nozadze (Jan 2017) Numerical modelling of fires in road tunnels with longitudinal ventilation system. Quality Access to Success, Vol. 18, S1, pp. 77-80.

[13] O. Lanchava, G. Abashidze, D. Tsverava (Jan 2017) Securing fire safety for underground structures. Quality Access to Success, Vol. 18, S1, pp. 47-50.

[14] J. Lia, Y.F. Li, C.H. Cheng, W.K. Chow (2019) A study on the effects of the slope on the critical velocity for longitudinal ventilation in tilted tunnels. Tunneling and Underground Space Technology, 89, pp. 262-265.

[15] A. Vaitkevicius, R. Carvel (2016) Investigating the Throttling Effect in Tunnel Fires. Fire Technology, Vol. 52, pp. 1619-1628.

[16] O. Lanchava, N. Ilias, G. Nozadze, S.M. Radu, R.I. Moraru, Z. Khokerashvili, N. Arudashvili (2017) The impact of the piston effect on the technological characteristics of ventilation in the subway tunnels. Proceedings of $8 \mathrm{th}$ International Symposium “Occupational Health and Safety” SESAM 2017, Bucharest, pp. 342-352.

[17] O. Lanchava, N. Ilias, G. Nozadze, S.M. Radu (Jan 2019) Heat and hygroscopic mass exchange modeling for safety management in tunnels of metro. Quality Access to Success, Vol. 20, S1, pp. 27-33.

[18] O. Lanchava, N. Ilias, G. Nozadze, S.M. Radu, R.I. Moraru, Z. Khokerashvili, N. Arudashvili (2019) FDS MODELLING OF THE PISTON EFFECT IN SUBWAY TUNNELS. Environmental Engineering and Management Journal. Vol. 18, No. 4, pp. 317-325.

[19] Y.Z. Li, B. Lei, H. Ingason (2010) Study of critical velocity and backlayering length in longitudinally ventilated tunnel fires. Fire Safety Journal, Vol. 45, pp. 361-370.

[20] NFPA 502 (2011) Standards for Road Tunnels, Bridges, and Other Limited Access Highways. National Fire Protection Association (NFPA).

[21] P.H. Thomas (1968) The Movement of Smoke in Horizontal Passages against an Air Flow. Fire Research Station. Boreham Wood, p. 8.

[22] C.K. Lee, R.F. Chaiken, J.M. Singer (1979) Interaction between duct fires and ventilation flow: an experimental study. Combustion Science and Technology. Vol. 20, pp. 59-72.

[23] N.H. Danziger, W.D. Kennedy (1982) Longitudinal ventilation analysis for the Glenwood canyon tunnels. Fourth International Symposium on the Aerodynamics \& Ventilation of Vehicle Tunnels, BHRA Fluid Engineering. 1982, pp. 169-186.

[24] W.D. Kennedy (1996) Critical velocity: past, present and future. Seminar of Smoke and Critical Velocity in Tunnels, JFL Lowndes, pp. 305-322.

[25] H. Wan, Z. Gao, J. Han, ... Y. Zhang (2019) A numerical study on smoke back-layering length and inlet air velocity of fires in an inclined tunnel under natural ventilation with a vertical shaft. International Journal of Thermal Sciences, Volume 138, pp. 293-303.

[26] O. Lanchava, N. Ilias (2020) Calculation of railway tunnels ventilation. Journal of Engineering Sciences and Innovation, Volume 5, Issue 1 / 2020, pp. 69-86. 